\title{
NON-STEROIDAL ANTI-INFLAMMATORY DRUGS (NSAIDS) AND PHYSIOTHERAPY - A SELECTIVE REVIEW
}

\begin{abstract}
This paper presents a selective review on the non-steroidal anti-inflammatory drugs (NSAIDs). These drugs, which form the mainstay of treatment of a variety of musculoskeletal and rheumatic conditions, may facilitate the efficacy of and compliance with physiotherapy treatment. Their mechanisms of action, adverse effects, various routes of administration, eg systemic versus topical, and the role that these drugs may play in physiotherapy practice are discussed.
\end{abstract}

\section{VAN DER BIJL P, BChD, PhD, DSc ${ }^{1}$; DE JAGER R, Physiotherapy student²; NEL CMM, Physiotherapy student'.}

\author{
${ }^{1}$ Professor and Head of the Department of Pharmacology, \\ Faculty of Health Sciences, University of Stellenbosch. \\ 2 Physiotherapy Students, Department of Pharmacology, \\ Faculty of Health Sciences, University of Stellenbosch.
}

KEY WORDS: NON-STEROIDAL ANTI-INFLAMMATORY DRUGS (NSAIDS), PHYSIOTHERAPY PRACTICE.

\section{INTRODUCTION}

In providing optimum health care, physiotherapists must utilise and understand all available and reasonable resources on behalf of their patients. These resources include not only interventions provided by themselves but also those offered by other health-related disciplines. Most patients presenting for physiotherapy treatment have received, or are are currently receiving, some form of pharmacotherapy often including self-prescribed "over-the-counter" (OTC) drugs. In addition to the fact that many of these medications may have an impact on the patient's response to physiotherapy, there are a number of therapeutically active agents, including topical preparations, that are used by physiotherapists (Rothstein 1995). It is especially in the field of musculoskeletal and rheumatic diseases that clinical benefits can be derived from specific groups of therapeutic agents such as the non-steroidal anti-inflammatory drugs (NSAIDs). These drugs relieve pain, reduce swelling and inflammation, increase mobility of muscles or joints, thereby facilitating the efficacy of and compliance with physiotherapy treatment (Whelan and Walker 1996).

While the efficacy of the NSAIDs in a variety of conditions associated with pain, swelling and inflammation has been well established, their significant toxicity profiles may limit their use. This is particularly the case in the elderly, a group of patients in which gastrointestinal side-effects are accentuated. In recent years a growing number of topical NSAIDs have become available on the market, a development largely prompted by the high incidence of serious gastrointestinal adverse events associated with the systemic use of NSAIDs. However, although these topically administered NSAIDs have better safety-profiles compared to systemic ones, mainly due to their lower plasma concentrations, they are expensive. Furthermore, apart from their beneficial role in musculoskeletal conditions, their efficacy in comparison with oral NSAIDs in other conditions, eg rheumatic diseases, is less well-defined.

This study selectively reviews the NSAIDs as well as the role that these agents may play in patient management by physiotherapists.

\section{MECHANISMS OF ACTION OF THE NSAIDS}

Surgery, trauma or infection of tissue causes the release of a variety of mediators of inflammation, including bradykinin, histamine and oxidation products of arachidonic acid (Figure 1) (Van der Bijl and Van der Bij1 2002). These chemical compounds are associated with the development of pain, swelling and inflammation. When cellular membranes are damaged, the enzyme phospholipase $\mathrm{A}_{2}$ releases fatty acids from membrane phospholipids. Phospholipase $\mathrm{A}_{2}$ can be inhibited by a group of proteins termed lipocortins (annexins), the synthesis of which is induced by glucocorticosteroids (Fig 1). Arachidonic acid, which is one of these liberated fatty acids, is then converted in the presence of oxygen by a cyclo-oxygenase (COX) enzyme to form biologically active compounds including prostaglandins, prostacyclins and thromboxanes (collectively known as the prostanoids) (Van der Bijl and Van der Bij1 2002). The prostaglandins as well as some of their unstable endoperoxide precursors, are potent mediators of pain, swelling and inflammation. Nociceptors (pain receptors) can be sensitized by prostaglandins to other inflammatory mediators, eg bradykinins and histamines, enhancing the pain and tenderness associated with inflammation. Additionally, prostaglandins amplify the blood vessel permeability initiated by bradykinin and histamine (Van der Bijl and Van der Bijl 2002). This results in vasodilatation and leakage of plasma from blood vessels (extravasation), these phenomena being clinically manifested as erythema (red-

\section{CORRESPONDENCE TO:}

Professor P van der Bijl

Department of Pharmacology,

Faculty of Health Sciences,

University of Stellenbosch

Private Bag X1, Tygerberg 7505

South Africa

Tel: +27-21-938 9331

Fax: +27-21-938 9122

E-mail:pvdb@sun.ac.za 


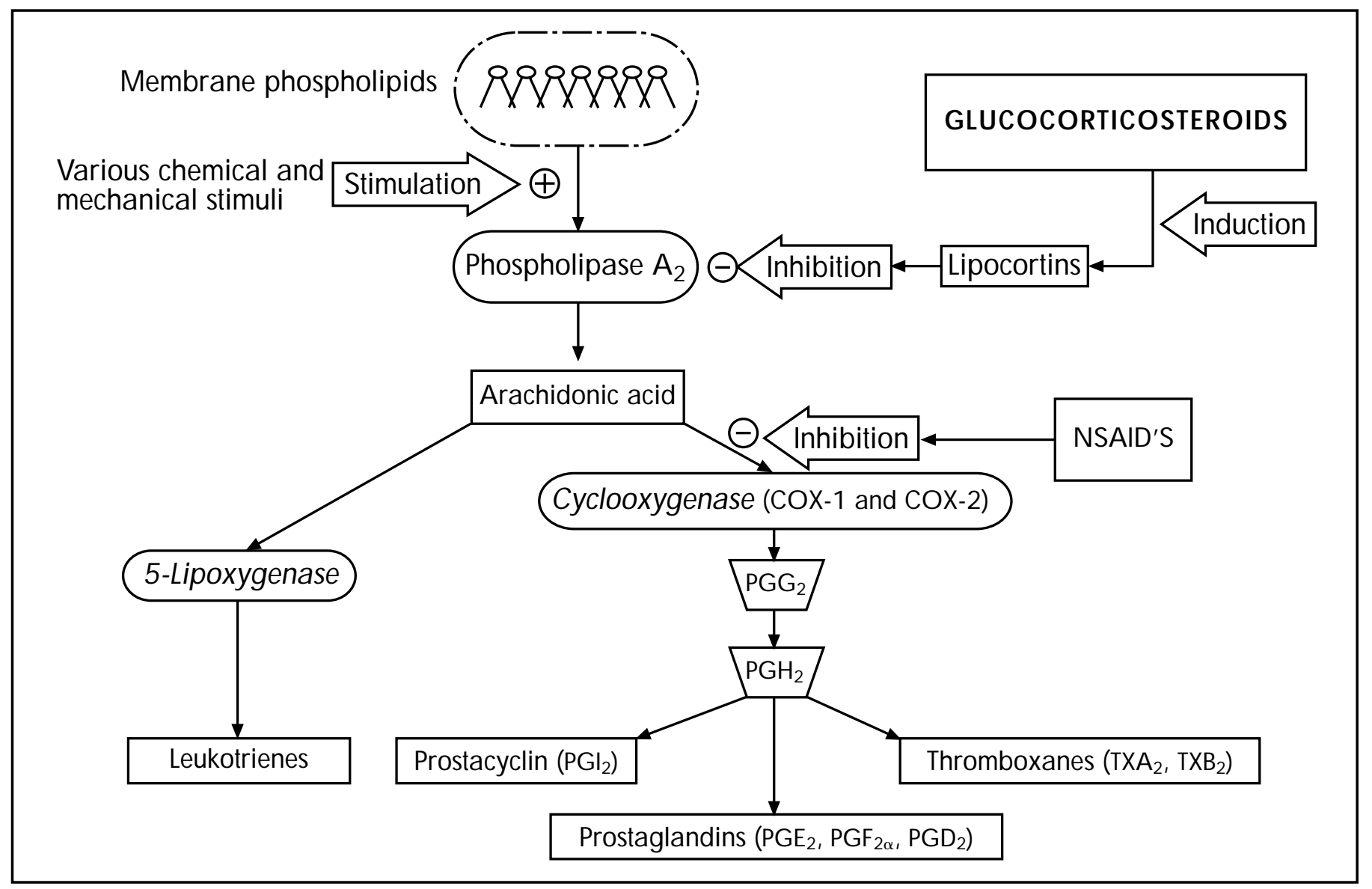

Figure 1: Mechanism of action of the NSAIDs

ness) and oedema (swelling), signs of inflammation lasting much longer than the initial stimulus of tissue injury. Although they comprise a chemically heterogeneous group of compounds, NSAIDs have a common mode of action in that they act on the above peripheral inflammatory and pain producing processes by inhibiting the COX enzyme (Figure 1). However, the COX enzyme also catalyses the formation of other prostanoids, eg prostacyclins and thromboxanes, compounds which are responsible for maintaining the integrity of the gastric mucosa, renal blood flow and normal blood platelet activation. Inhibition of the COX enzyme is therefore reponsible not only for the therapeutic efficacy of the NSAIDs, but also for some of the toxic effects reported for these agents. At least two isoforms of the COX enzyme exist ie, COX-1 and COX-2. Both these isoenzymes have separate functions and are subject to different regulatory mechanisms (Van der Bijl and Van der Bijl 2002). COX-1 is a constitutive ("housekeeping") isoenzyme and generates prostaglandins with cyto- protective functions as well as regulating normal cell activities in the gastric mucosa, kidneys and blood platelets. On the other hand, the isoenzyme COX-2 is a gene product induced by pro-inflammatory stimuli in inflammatory cells following injury and inflammation. However, the precise physiological functions of COX-2 are currently unclear. Because activation and release of the COX-2 isoenzyme by macrophages, monocytes, synovial cells, leucocytes and fibroblasts is slow, inflammatory responses mediated by this enzyme only occur after 1 to 3 hours. Most currently available NSAIDs inhibit both COX-1 and COX-2 enzymes to the same degree and in approximately equal dosages and concentration ranges. Long-term use of these conventional COX-1 and COX-2 inhibiting NSAIDs leads to adverse upper gastrointestinal effects, including increased mortality from serious peptic ulcers. The discovery of the inducible COX-2 isoform of cyclo-oxygenase approximately a decade ago, has therefore not surprisingly led to an intensive search for and introduction of drugs which selectively inhibit this specific isoenzyme. These COX-2 specific inhibiting NSAIDs, of which celecoxib and rofecoxib are examples, produce analgesic, antipyretic and anti-inflammatory effects while leaving the cytoprotective COX-1 enzymes intact. In this way toxic effects on the gastrointestinal mucosa and other tissues are kept to a minimum. Table 1 shows examples of conventional (COX-1 and COX-2 inhibiting) NSAIDs. Only two specific COX-2 inhibiting NSAIDs are currently available in South Africa (Table 2). All currently topically available NSAID preparations available on the South African market contain a non-specific COX inhibitor (Table 3).

\section{ADVERSE EFFECTS}

NSAIDs cause substantial dose-related morbidity and even mortality due to complications associated with peptic ulcers, eg perforation and bleeding. Many factors are involved in NSAIDinduced gastrointestinal injury and both prostaglandin-dependent and independent facets are involved. In the USA alone, approximately 107000 hospitalisations 
Table 1: Some generic and selected trade names for systemic N SAIDs (non-specific COX-1 and COX-2 inhibitors)

\begin{tabular}{|l|l|l|}
\hline \multicolumn{1}{|c|}{ Drug } & \multicolumn{1}{|c|}{ Trade name } & \multicolumn{1}{c|}{ Adult O ral Dose } \\
\hline Ibuprofen & Brufen, Inza + others & $400-800 \mathrm{mg} / 8 \mathrm{~h}$ \\
\hline Naproxen & Naprosyn, Synflex + others & $250-500 \mathrm{mg} / 12 \mathrm{~h}$ \\
\hline Flurbiprofen & Froben + others & $100 \mathrm{mg} / 12 \mathrm{~h}$ \\
\hline Ketoprofen & O rucote + others & $100-150 \mathrm{mg} / 12 \mathrm{~h}$ \\
\hline Diclofenac & Voltaren, Panamor + others & $25-50 \mathrm{mg} / 8 \mathrm{~h}$ \\
\hline Piroxicam & Feldene, Adco-Piroxicam +others & $20 \mathrm{mg} / 24 \mathrm{~h}$ \\
\hline
\end{tabular}

Table 2: Some generic and selected trade names for systemic N SAIDs (specific COX-2 inhibitors)

\begin{tabular}{|c|l|c|}
\hline Drug & \multicolumn{1}{|c|}{ Trade name } & Adult O ral Dose \\
\hline Celecoxib & Celebrex & $100-200 \mathrm{mg} / 12 \mathrm{~h}$ \\
\hline Rofecoxib & Vioxx & $12.5-25 \mathrm{mg} / 24 \mathrm{~h}$ \\
\hline
\end{tabular}

Table 3: Some generic and selected trade names for topical NSAIDs (non-specific COX inhibitors)

\begin{tabular}{|l|l|l|}
\hline \multicolumn{1}{|c|}{ Drug } & \multicolumn{1}{|c|}{ Trade name } & Adult Oral Dose \\
\hline $\begin{array}{l}\text { Diclofenac } \\
\text { diethylammonium }\end{array}$ & Voltaren Emulgel & $2-4 \mathrm{~g} / 6-8 \mathrm{~h}$ \\
\hline $\begin{array}{l}\text { Diclofenac } \\
\text { diethylammonium }\end{array}$ & Zeroflam & $2-4 \mathrm{~g} / 6-8 \mathrm{~h}$ \\
\hline $\begin{array}{l}\text { Diclofenac } \\
\text { Sodium }\end{array}$ & A thru-Derm & apply $6-8 \mathrm{~h}$ \\
\hline Indomethacin & Adco-indogel & apply $6-8 \mathrm{~h}$ \\
\hline Ketoprofen & Fastum & $5-15 \mathrm{~cm} / 12-24 \mathrm{~h}$ \\
\hline Ibuprofen & Ibuleve & apply $8 \mathrm{~h}$ \\
\hline Ketoprofen & O rucote G el & $4 \mathrm{~g} / 6 \mathrm{~h}$ \\
\hline Piroxicam & Rheugesic & $3 \mathrm{~cm} / 6-8 \mathrm{~h}$ \\
\hline Flurbiprofen & Transact & $1 \mathrm{patch} / 12 \mathrm{~h}$ \\
\hline
\end{tabular}

and 16500 deaths occur each year and these are associated with the use of non-selective NSAIDs (Goldstein 2000). Prior to the occurrence of these adverse events, chronic symptoms of dyspepsia may be absent, making NSAID-related toxicity difficult to predict and prevent. When patients at above-average or high risk, ie those with previous gastric ulcers, upper gastrointestinal bleeding, those over 65 years of age, concomitant corticosteroid or oral anticoagulant use and those using higher doses and/or are receiving multiple NSAIDs are involved, prophylactic therapies are recommended (Goldstein 2000; Hawkins and Hanks 2000). These therapies include using the prostaglandin analogue, misoprostol
(Cytotec $\left.{ }^{\circledR}\right)$ and/or concomitant administration of proton pump inhibitors, eg omeprazole (Losec $\left.{ }^{\circledR}\right)$. Fixed dose drug combinations of eg diclofenac and misoprostil (Arthrotec $\AA$ ), which is more cost effective than prescribing both agents separately, are now also available.

Other adverse effects of NSAIDs include sodium and water retention, renal impairment, bronchospasm and hypersensitivity (allergic) reactions. Drug interactions with NSAIDs occur and they should not be taken by patients on highdose methotrexate, anticoagulants (eg warfarin) or following consumption of alcohol. NSAIDs should also be avoided in elderly patients or those with impaired renal function who are taking digoxin or other NSAIDs (Roberts and Morrow 2001). The interaction potential of NSAIDs in patients taking lithium is currently under investigation.

\section{SYSTEMIC NSAIDS IN PHYSIOTHERAPY}

All currently registered NSAIDs available on the South African market are Schedule 3 substances, but physiotherapists may recommend these drugs to patients, who in turn may purchase them from pharmacies. In the latter case these drugs revert to Schedule 2 substances and may be dispensed, for a period of up to 5 days, for post-traumatic pain, swelling and inflammation (Medicines and Related Substances Control Act 1965). However, it remains the duty of the physiotherapist to familiarise her/ himself with the proper usage, contraindications, potential adverse effects and drug interactions associated with these drugs. Failing to comply with these prerequisites, may have medico-legal implications.

\section{TOPICAL NSAIDS IN PHYSIOTHERAPY}

Topical NSAIDs, which are Schedule 1 substances (Medicines and Related Substances Control Act 1965), are available in a number of different formulations for transcutaneous administration. The stratum corneum forms the protective layer that serves as a barrier to prevent drying out of the underlying tissues as well as the ingress of deleterious substances from the environment, including agents applied to the skin (Byl 1995). This layer is therefore considered to be the rate-limiting barrier in percutaneous drug delivery. The next layers comprise the viable but avascular epidermis, the basement membrane and the bloodvessel-containing dermis. Hereafter, the drug reaches the systemic circulation or penetrates into deeper tissues. For many years it was thought that percutaneous drugs all entered the dermal capillary network and reached the central blood compartment only to return to the local area above which they were applied. However, it now appears that there is a system of local delivery separate from systemic delivery via the central blood compartment (Byl 1995). Drugs that possess hydrophilic and hydrophobic properties are best absorbed 
through the various layers of human skin. Apart from chemical enhancers, which mainly target the lipids in the stratum corneum other physical methods, eg iontophoresis and ultrasound have also been used in an effort improve transcutaneous drug uptake (Byl 1995).

Although the systemic adverse effects described above may occur with topically applied NSAIDs, the incidence compared with orally administered forms is much lower, the maximal blood levels of the former being only 5 to $15 \%$ of those of the latter (Heyneman et al 2000). Because NSAID-toxicity is often doserelated, a reduction in blood concentrations should also diminish the risk of potentially serious systemic adverse effects. However, allergic responses to the topically applied forms of these drugs may still occur as well as adverse cutaneous effects such as rash and pruritis at the site of application.

Although a wide variety of NSAIDs, including indomethacin, ketoprofen, diclofenac, piroxicam, tenoxicam, ketorolac and aceclofenac have been studied with regard to their transdermal diffusion, their passage across skin is not always optimal (Singh and Roberts 1994; Cordero et al 1997; Wenkers and Lippold 2000; Santoyo and Ygartua 2000). However, numerous human and animal experiments have demonstrated that topically applied NSAIDs reach lower plasma concentrations than their systemically administered forms, while their soft tissues levels are still high enough to exert anti-inflammatory effects (Vaile and Davis 1998). A significant number of studies of soft tissue conditions have demonstrated the superiority of topical NSAIDs over placebo and have suggested equivalent efficacy of topical compared to some oral forms. For rheumatic diseases, the evidence available suggests, but does not document, that topical NSAIDs are as efficaceous as orally administered equivalents (Heyneman et al 2000).

\section{CONCLUSIONS}

Apart from their classic treatment modalities, physiotherapists can contribute to the well-being of their patients by the judicious use of systemic and topical NSAIDs in acute musculoskele- tal and, possibly, rheumatic conditions. These drugs can reduce pain, stiffness, movement limitations or swelling associated with either soft tissue injuries or rheumatic dysfunction. However, conclusive evidence on the role of these drugs as adjuvants to physiotherapy needs to be established. Because all NSAIDs are not equipotent and there exists considerable variability in patient response to these drugs, it is not always predictable which agent will be the most effective in a particular patient. A need therefore exists for physiotherapists to be trained in the proper use of NSAIDs and to study their efficacy, when combined with with physiotherapeutical interventions, in a variety of disorders.

Evidence is accumulating for the beneficial role that topically administered NSAIDs may play in the management of acute soft-tissue injuries, however, large clinical, double-blind, placebocontrolled trials over longer periods are still required to define their precise role in these post-traumatic events (Vaile and Davis 1998). While there is still insufficient data to unequivocally demonstrate widespread clinical benefits of topical NSAIDs in rheumatic diseases, some evidence does suggest certain advantages in their topical delivery for these conditions (Heyneman et al 2000). By actively participating in studies involving these topical NSAIDs, physiotherapists may make valuable contributions to our understanding of the efficacy of these drugs. Although there is a decrease in systemic adverse reactions with topical NSAIDs, side-effects, which are mostly cutaneous, infrequent and minor, do occur and long-term data need to be obtained. Here too, the physiotherapist trained in pharmacology can be of great help in the surveillance of adverse drug reactions. Furthermore, the topical application of these drugs may also be fruitfully combined with manual techniques (eg massage), or electrotherapy (eg iontophoresis or ultrasound), which may enhance cutaneous uptake (Byl 1995).

We conclude that more physiotherapists should become involved in research related to optimising the use of systemic and topical NSAIDs, both for the benefit of their patients and for advancing their profession.

\section{REFERENCES}

Byl N 1995. The use of ultrasound as an enhancer for transcutaneous drug delivery: phonophoresis. Physical Therapy 75:539-553

Cordero JA, Alarcon L, Escribano E, Obach R, Domenech J 1997. A comparative study of the transdermal penetration of a series of nonsteroidal antiinflammatory drugs. Journal of Pharmaceutical Science 86:503-508

Goldstein JL 2000. Who needs prophylaxis of nonsteroidal anti-inflammatory drug-induced ulcers and what is optimal prophylaxis? European Journal of Gastroenterology and Hepatology 12 Suppl 1S11-15

Hawkins C, Hanks GW 2000. The gastroduodenal toxicity of nonsteroidal anti-inflammatory drugs: a review of the literature. Journal of Pain and Symptom Management 20:140-151

Heyneman CA, Lawless-Liday C, Wall GC 2000. Oral versus topical NSAIDs in rheumatic diseases. Drugs 60:555-574

Medicines and related Substances Control Act (Schedules 1 and 3) No. 101 of 1965. In: Compendium of Laws and Regulations Relating to Pharmacy (Volume 1, 2001), pp164-169 and pp176-184. Butterworth, Durban

Roberts LJ, Morrow JD 2001. Analgesicantipyretic and antiinflammatory agents and drugs employed in the treatment of gout. In: Hardman JG, Limbird LE, Gilman AG (eds) Goodman \& Gilman's-The Pharmacological Basis of Therapeutics, pp687-731. McGrawHill, New York

Rothstein JM 1995. Pharmacology and physical therapy. Physical Therapy 75:341

Santoyo S, Ygartua P 2000. Effect of skin pretreatment with fatty acids on percutaneous absorption and skin retention of piroxicam after its topical application. European Journal of Pharmaceutics and Biopharmaceutics 50:245-250

Singh P, Roberts MS 1994. Skin permeability and local tissue concentrations of nonsteroidal anti-inflammatory drugs after topical application. Journal of Pharmacology and Experimental Therapeutics 268:144-151

Vaile JH, Davis P 1998. Topical NSAIDs for musculoskeletal conditions. Drugs, 56:783-799

Van der Bijl, Van der Bijl P 2002. NSAIDs in orofacial pain management - an update. South African Dental Journal 57: 328-331

Wenkers BP, Lippold BC 2000. Prediction of the efficacy of cutaneously applied nonsteroidal anti-inflammatory drugs from a lipophilic vehicle. Arzneimittelforschung 50:275-280

Whelan AM, Walker JM 1996. Pharmacology and the interaction with physical therapy. In: Walker JM, Helewa A (eds). Physical Therapy in Arthritis, pp 149-174. WB Saunders Company, Philadelphia 